\title{
Awakening professionals' critical awareness of health literacy issues within a francophone linguistic-minority population in Ontario
}

\section{S. Zanchetta, PhD (1); C. Maheu, PhD (2); C. Fontaine, BA (3); L. Salvador-Watts, BScN (4); N. Wong, BScN (5)}

This article has been peer reviewed.

Tweet this article

\begin{abstract}
Introduction: We carried out a qualitative evaluation of immediate learning and attitudinal change among health care and social services professionals who attended a workshop promoting critical reflection about health literacy among linguistic-minority Franco-Ontarians.

Methods: The study involved 41 francophone health care and social services professionals. The workshop facilitator used evocative objects to elicit reflection on health literacy. Data sources were audio-recordings of group discussions and feedback forms completed by participants.
\end{abstract}

Results: The study found that the workshop awakened participants' awareness of health literacy and stimulated them to promote health literacy in their professional practice. The workshop also broadened participants' vision of health literacy as a social determinant of health that interacts synergistically with culture, age, immigration status, social support, and socioeconomic status.

Conclusion: Professionals expressed their awakened awareness of health literacy as collective accountability. This corroborates our claim that critical pedagogy applied to in-service education effectively stimulates professionals' awareness of their potential to change their practice and work environment.

Keywords: evaluation study, francophone linguistic minority, minority health, training activities

\section{Introduction}

Health literacy (HL) is considered to be a stronger social determinant of health than age, gender, education, race, employment or socioeconomic status. ${ }^{1}$ Clients' knowledge of chronic disease self-management can be predicted by their HL. ${ }^{2}$ Selfmanagement requires building capacity to care for oneself and increase one's autonomy. These steps are most likely achieved through participatory learning, a methodology used in health education programs to inform health care professionals about asthma, hypertension, AIDS, tuberculosis and other chronic diseases. ${ }^{3-5}$ In Canada, participatory learning has been used to strengthen self-management by building HL, ${ }^{6}$ which is difficult to do when health information is presented in a language other than one's first language. ${ }^{7}$

In this article, we address 1) the attitudes toward HL of francophone professionals born in Canada and elsewhere who live as linguistic minority in Ontario, and 2) the HL issues these professionals report facing when working with francophone clients.

We define "francophone" as having French as first language ${ }^{8}$ and being able to use it conversationally. ${ }^{9}$ Being a francophone linguistic minority encompasses ethnolinguistic identity, social identity and the affective meaning of these identities. ${ }^{10}$

After Quebec, Ontario has the secondhighest proportion of francophone immigrants in Canada; $10.3 \%$ of these francophone immigrants are ethno-cultural minorities and of these, $86 \%$ live in linguistic-minority situations. ${ }^{11,12}$ Ontario also has a high proportion of senior "native" francophones with low levels of general literacy. ${ }^{13}$ Although there is no specific information on francophone health care professionals in Ontario, Canadian health care professionals generally lack awareness of the nature, significance and impact of $\mathrm{HL}^{14}$ on their linguistic-minority clients. We present findings from an evaluation study of a workshop held with francophone health and social services professionals. The goal of the workshop was to identify and appraise professionals' knowledge of HL among their francophone linguistic minority clients and to promote HL best practices by addressing clients' health needs and willingness to be accountable for their health.

Author references:

1. Daphne Cockwell School of Nursing, Faculty of Community Services, Ryerson University, Toronto, Ontario, Canada

2. Ingram School of Nursing, Faculty of Medicine, McGill University, Montréal, Quebec, Canada

3. Regroupement des intervenants francophones en santé et en services sociaux de l'Ontario (Rifssso), Toronto, Ontario, Canada

4. Family Birthing Centre, St. Joseph's Health Centre, Toronto, Ontario, Canada

5. General Internal Medicine, Toronto Western Hospital, Toronto, Ontario, Canada

Correspondence: Margareth S. Zanchetta, Daphne Cockwell School of Nursing, Faculty of Community Services, Ryerson University, 350 Victoria St, POD 468E, Toronto, ON M5B 2K3;

Tel.: 416-979-5000 ext. 4557; Fax: 416-979-5332; Email: mzanchet@ryerson.ca 


\section{Background}

A surprisingly high proportion of Canadian adults- $42 \%$ of working-age adults (16 to 65 years) and $56 \%$ of francophones-find it difficult to understand the content of written material in their mother tongue. ${ }^{13}$ Such a lack of comprehension decreases HL and affects health care costs ${ }^{15,16}$ because the motivation to adhere to health promotion principles requires the ability to assess health information. ${ }^{17}$ The link between HL and disparities in access to health care among linguistic-minority Canadian francophones remains relatively unexplored. ${ }^{18}$ The literature on HL in this population is also scarce as are evaluations of $\mathrm{HL}$ interventions or professional in-service education about HL. Our evaluation study addresses this knowledge gap.

Multiple definitions of HL are rooted both in the perspective of social determinants of health and disease self-management. ${ }^{19}$ As a social determinant of health, HL is lifelong, socially constructed knowledge ${ }^{7}$ that encompasses reading, writing, listening, speaking, numeracy and critical thinking-which are all deeply influenced by language and culture. ${ }^{20} \mathrm{HL}$ acts synergistically with other social determinants of health (e.g. access to health care, age, culture, location, education, income) to influence health status. HL also forms the basis for health beliefs, health decisions or lifestyle choices ${ }^{21}$ and how people navigate complex health care systems. Poor or inadequate HL therefore tends to contribute to inequities of access to health care. $^{22}$

From the perspective of disease selfmanagement, HL is a set of measurable cognitive skills (e.g. writing, reading, counting) that enable a conceptual understanding of health, adequate use of health services, safe decision-making and adherence to medical treatments and regimens. ${ }^{23}$ HL measurements can predict approximate health behaviours, health outcomes, health-promoting behaviours and health care system inequities ${ }^{24}$ as well as visits to the emergency department and high health care costs related to poor understanding of health information and disease management in general. ${ }^{25,26}$ High
HL is also associated with satisfaction with health services, optimism about care and trust in health care systems and professionals. $^{27}$

In this study, we used the social determinants of health definition of HL, intertwined with tenets of health communication $^{28}$ and critical literacy. ${ }^{15}$ Within such a combined perspective, HL comprises multidimensional processes of social learning (e.g. accumulation of family, school, social, cultural and professional assets) that incorporate health-related values, beliefs, fears and behaviours. The roots of HL include (1) health culture and health knowledge, (2) the type of health education to which a person is exposed, (3) practice in searching, reading, decoding and communicating health information, (4) ability to use numerical health information to solve health problems, and (5) applying other forms of literacy to interpret the world. ${ }^{7}$ $\mathrm{HL}$ is understood within a perspective of synergism among other determinants that goes beyond the individual's will and skills to self-manage her/his health conditions.

\section{Literature review}

Ideas about critical literacy as an avenue to helping people make social change, such as Freire's ${ }^{29}$ approach of critical awareness in education, have guided evaluation studies of practice-renewal workshops for health care and social services professionals. Freire's approach helps professionals' reflect on their work and their agency within their political, socioeconomic and professional contexts. ${ }^{3}$ Reported outcomes of those studies include a commitment to facilitating clients' empowerment, improved understanding of clients and more reflection on challenges in communication. ${ }^{30}$ Concepts of critical awareness, empowerment, emancipation and participatory learning as related to professionals and clients have guided health-promotion initiatives for the last 3 decades. ${ }^{31,32}$ It is noteworthy that, despite enhanced HL being an expected outcome of health promotion initiatives, these concepts are neither synonymous nor interchangeable.

\section{Conceptual framework}

In his philosophy of education, Freire defines "critical consciousness"29,33 as the process of recognizing one's own world and one's place in this world, and taking part in transforming it. ${ }^{34}$ Critical consciousness is a means for reflection within the process of action-reflectionaction. Sharing critical dialogue with others in the learning process co-creates new knowledge. Freire postulates that the awareness raised from learning may motivate learners to identify for themselves the most appropriate means to solve problems they face in their lives. In other words, learners' understanding of how their social reality affects learning helps them recognize the need to defy existing oppressive conditions, consider alternatives and then set learning goals related to personal educational outcomes. ${ }^{33,35}$

Freire's approach guided the design and development as well as the evaluation of our HL workshop for francophone professionals. Freire's concept of critical consciousness $^{36}$ was particularly well suited to this workshop because the francophone participants were all aware of the statusbased historical oppression of their linguistic minority in Canada. The silence about this oppression led to the loss of cultural, social, community and ethnic identity among linguistic-minority francophones, along with non-francophones' perception that the French language belongs to a historically colonized, minority population. ${ }^{37}$

\section{Methods}

\section{Research questions}

We conducted an evaluation study of the workshop "Placing Health Literacy at the Core of Your Practice" with francophone health and social services professionals to disseminate empirical information on HL and elicit reflection on HL among their clients.

The following questions guided the evaluation study:

- How did the workshop expand the participants' visions of HL? 
- Which attitudes, skills, motivations or intended behaviours did the workshop influence?

- Can changes in participants' understanding of their clients and service provision be attributed to the workshop?

\section{The health literacy awakening workshop}

The aim of the workshop "Placing Health Literacy at the Core of Your Practice” was to update professionals' knowledge of HL and make them aware of 2 major problems associated with HL and the health of francophones: 1) the dearth of knowledge in the literature and among francophone professionals about social determinants of health and the specific needs of francophone linguistic minorities, ${ }^{10}$ and 2) low awareness of HL among Canadian health care and social service professionals. ${ }^{14}$ We used a constructivist approach in which social dialogue leads to learning based on self-reflection about the learner's own social constructions ${ }^{38}$ as well as how knowledge enables people to pursue goals in multiple contexts. ${ }^{39}$

Because this was an awareness-awakening workshop, participants' knowledge was not measured before and after the workshop. Evidence of learning emerged from individual self-reflection and group discussions. ${ }^{31}$ The workshop was held in the three Ontario cities where the majority of francophone health and social service professionals live: Sudbury (in December 2008), Toronto (in January 2009) and Ottawa (in February 2009). The 6-hour workshop was offered once in each city, and the number of participants ranged from 9 to 18 .

Empirical information presented in the workshop included Canadian statistics on literacy levels and research findings on HL published by the Canadian Council of Learning $^{22}$ and available on their website, ${ }^{40}$ from Health Consortium for Francophone Populations, ${ }^{41}$ and from the Canadian Public Health Association and its associated researchers. ${ }^{6,14}$ The workshop required participants to work with evocative objects (e.g. photographs, drawings or objects) that sustained the dialectical dialogue between the workshop facilitator and the participants ${ }^{42}$ and that were used to 1) recall experiences and known social realities and recognize learners' own ideas, 2) create analogies to guide learners' self-reflection on their practice to help them transform it, and
3) encourage learners to reflect on their own experiences and decide on how to act on them. To ensure consistency among the workshop presentations, the facilitator (MZ) chose and brought the same evocative objects to all 3 workshops.

Table 1 describes the workshop components. These used Freire's ${ }^{29}$ concept of action-reflection-action, evocative objects and critical dialogue.

\section{Recruitment of workshop attendees and study participants}

To produce an in-depth understanding of the workshop's immediate outcomes, we collected detailed information about our participants through a qualitative evaluation study. ${ }^{43}$ Ethics approval to conduct the study was obtained from York University Research Ethics Board. Where participants consented, we audio-recorded their accounts.

Workshop participants comprised francophone professionals born in Burkina Faso, Haiti, Lebanon, Morocco and Canada who worked in the social service and health sectors (including project managers), policy making and public advocacy. Students in the health and social disciplines also

TABLE 1

Description of the workshop "Place Health Literacy at the Core of your Practice"

\begin{tabular}{|c|c|c|c|}
\hline Facilitator's presentation topics & Exercise 1 & Exercise 2 & Evaluation \\
\hline $\begin{array}{l}\text { Statistical data on literacy and HL, using } \\
\text { local data about workshop location } \\
\text { Overview of scientific evidence on HL } \\
\text { Review of HL conceptual definitions } \\
\text { Discussion of the many HL definitions } \\
\text { Interactive exercise comparing } \\
\text { functional skills of generally } \\
\text { literate and illiterate }{ }^{\text {a }} \text { individuals } \\
\text { Discussion of social determinants } \\
\text { of health related to low HL among } \\
\text { francophone linguistic-minority } \\
\text { Interactive discussion about participants' } \\
\text { comprehension of presentation, } \\
\text { incorporating their personal and } \\
\text { professional experiences }\end{array}$ & $\begin{array}{l}\text { Goal: Promote application and } \\
\text { comprehension of HL concept } \\
\text { through metaphors/analogies } \\
\text { Create discussion groups } \\
\text { Distribute evocative objects to } \\
\text { each participant } \\
\text { Individually reflect on the } \\
\text { presentation, HL, concept } \\
\text { and ideas evoked by objects } \\
\text { Participants individually presented } \\
\text { on metaphors and analogies } \\
\text { evoked by objects } \\
\text { Facilitator concluded exercise by } \\
\text { synthesizing participants' } \\
\text { presentations }\end{array}$ & $\begin{array}{l}\text { Goal: Provoke critical reflection } \\
\text { about essential competencies } \\
\text { for HL within the professional } \\
\text { context to awaken professionals' } \\
\text { consciousness of HL } \\
\text { Discussion in groups about } \\
\text { essential competencies to } \\
\text { incorporate HL into practice } \\
\text { and the support needed at } \\
\text { organization and community } \\
\text { level to improve professionals' } \\
\text { knowledge and competencies of HL } \\
\text { Short presentation by each group } \\
\text { about support needs they } \\
\text { identified } \\
\text { Facilitator concluded exercise by } \\
\text { synthesizing groups' key ideas }\end{array}$ & $\begin{array}{l}\text { Distribution of form asking for: } \\
\text { Evaluation of workshop's contribution } \\
\text { to participants' learning of HL } \\
\text { Awareness of francophone linguistic- } \\
\text { minority difficulties in receiving } \\
\text { services in French } \\
\text { Awareness of importance of } \\
\text { linguistically/culturally appropriate } \\
\text { health and social services } \\
\text { Requested suggestions for future } \\
\text { workshop }\end{array}$ \\
\hline
\end{tabular}

Abbreviation: HL, health literacy.

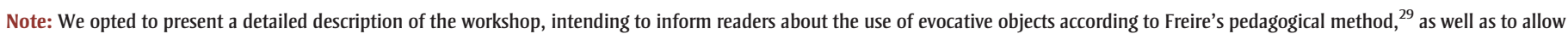
its replication.

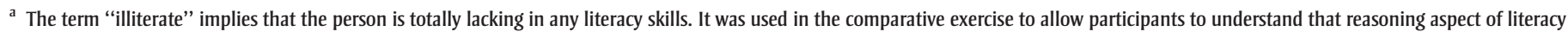
does not depend on reading skills. 
participated in the workshop (see Table 2).

All 44 workshop participants were Rifssso members and were recruited (by CF) through that organization's listserve. We did not use any criteria to select participants, and the sample size was determined by the number of people who applied to join the study at the beginning of the workshop. As a result, it was not possible to have an even distribution among the participants' areas of practice.

A team member (CF) explained the benefits and risks of participating in the evaluation and the participants' right to stop the audiorecording. A question period followed, and the participants were then invited to review and sign the consent forms. Of the 44 workshop participants, 41 agreed to participate in the evaluation study (see Table 2). When those workshop participants who did not agree to take part in the evaluation study spoke, audio-recording was paused.

\section{Data collection and analysis}

A total of 17 recorded hours were transcribed verbatim. In addition, the participants were asked to complete feedback forms that asked how the workshop had contributed to their knowledge of HL and their awareness of HL-related problems encountered by their clients. Verbatim transcripts and feedback forms underwent manual content analysis ${ }^{44}$ using the following process:

\section{1) reading all transcripts;}

2) grouping descriptive and explanatory ideas;

3) creating clusters of meaning composed of words and sentences;

4) identifying dichotomies within the categories (e.g. positive/negative, favourable/unfavourable);

5) organizing evidence of the impact of learning about HL into 3 conceptual categories:

- expanded knowledge,

- changes in attitude, and

- anticipated changes in professional practice;

6) identifying features of the following emergent themes:

- acknowledging the various dimensions of HL (prevention, self-management of health, right to access services, equity in services, language as a social determinant of health),

TABLE 2

Distribution of "Place Health Literacy at the Core of your Practice" workshop attendees, by city and professional sector

\begin{tabular}{|c|c|c|c|}
\hline City & Sector $^{a}$ & Profession and scope of activity & $\mathbf{N}$ \\
\hline \multirow[t]{4}{*}{ Sudbury } & Health & $\begin{array}{l}\text { Registered nurses, physiotherapy faculty, dietician, senior } \\
\text { community health, community organizers, community developer }\end{array}$ & 7 \\
\hline & Social services & Social worker & 1 \\
\hline & Education & Social sciences college faculty & 1 \\
\hline & Subtotal & & 9 \\
\hline \multirow[t]{4}{*}{ Toronto } & Health & $\begin{array}{l}\text { Health educators, nursing undergraduate student, project manager, } \\
\text { psychologist, consultant }\end{array}$ & 6 \\
\hline & Social services & $\begin{array}{l}\text { Social workers, community workers, policy maker, anthropologist, } \\
\text { communication professionals, project coordinators, accountant }\end{array}$ & 10 \\
\hline & Education & Social sciences college faculty & 1 \\
\hline & Subtotal & & 17 \\
\hline \multirow[t]{4}{*}{ Ottawa } & Health & $\begin{array}{l}\text { Midwife, nursing students, physician, project manager, public } \\
\text { advocate, project coordinators, registered nurses }\end{array}$ & 14 \\
\hline & Social services & Social sciences college student & 1 \\
\hline & Education & High school teacher, nursing university faculty, school administrator & 3 \\
\hline & Subtotal & & 18 \\
\hline Total & & & 44 \\
\hline
\end{tabular}

Abbreviation: Rifssso, Regroupement des intervenants francophones en santé et en services sociaux de l'Ontario.

${ }^{a}$ These sectors are most likely representative of Rifssso members' areas of professional activity.
- broadened vision of health (environment, education, economy, gender, social network, age), and

- awakening critical awareness (HL levels among francophones, life in linguistic-minority situations);

7) rereading the transcripts while applying the themes;

8) analyzing associations between themes; and

9) re-analyzing the transcripts to identify whether HL consciousness was awakened.

MZ, LS and NW, who are fluent in French but not native speakers, analyzed the data. Afterwards, four francophone professionals who live in linguistic-minority situations in Ontario verified the findings. As natural experts, $\mathrm{CM}$ and $\mathrm{CF}$ confirmed the original interpretation of the findings. ${ }^{45}$ Two other francophone professionals with experience in the health and education sectors also reviewed an early draft of the manuscript. Original quotes were translated into English for this paper by LS, and the translation's accuracy was confirmed by the francophone co-authors.

\section{Results}

At registration, only 3 workshop participants knew about HL. After the facilitator's presentation, most of the evaluation study participants reported that this was the first time they had heard about HL in the context of health and social services and HL's significance to their clients:

It's the first time that I hear about health literacy. The extent to which this literacy is present in our daily work and to which it is important that we understand it, in order to help the Canadian senior population, is remarkable. [Sudbury participant]

When the facilitator used the Canadian Council on Learning's online interactive map of Ontario ${ }^{46}$ to show literacy and reading levels, the participants immediately related to this their clients' HL reality. Afterwards, they discussed how low literacy interferes with their efforts to enhance their 
clients' HL if they mainly have printed materials to use.

\section{Participants' preliminary ideas about health literacy}

The personal and professional stories that the workshop participants shared during Exercise 1 (see Table 1) demonstrated their expanding awareness of the consequences of low HL. Access to health information was a key issue in group discussions. Four interlinked ideas emerged: (1) how HL influences whether or how clients understand health information; (2) the importance of listening to clients; (3) the necessity of professionals producing simple, clear health information; and (4) the need for professionals to delve below the superficial presentation of health information.

Evocative objects inspired various ideas. A bottle of nail polish, for example, evoked society's standards for women's health, nail care, body image, the cost of manicures and being at times forced to choose between paying for food and beauty products; a baby bottle evoked the risk of milk contamination from poor-quality plastic as well as infants' poor oral hygiene; a can of tuna evoked reading difficulties due to the small font on cans and misinterpretation of nutritional information. (For other examples, see Table 3.)

\section{Participants' reflections on health literacy and experiences with disease}

The participants reflected on how poorly clients with low HL understand the probability, a concept that is often used in explaining diagnostic and prognostic information. Lack of health educational material responsive to HL issues and help in decoding health information aggravates the effect of clients' low numerical literacy. As a result, clients prefer less stressprovoking health information, for example, that the probability of not developing cancer is $95 \%$ rather than that there is a $5 \%$ probability of developing cancer. Numerical literacy is needed to interpret health information that, for example, requires clients to keep track of the fats, carbohydrates and calories in their diet. The participants also pointed out that clients need technological and computer literacy to handle medical machines and electronic medical supplies.

Some participants noted that their francophone clients strategically navigate health information in their second language by

TABLE 3

Ideas generated by evocative objects used in the "Place Health Literacy at the Core of your Practice" workshop exercises

\begin{tabular}{|c|c|c|}
\hline $\begin{array}{l}\text { Conceptual } \\
\text { categories }\end{array}$ & Evocative object & Ideas flowing from objects \\
\hline \multirow[t]{2}{*}{$\begin{array}{l}\text { Expanded } \\
\text { knowledge }\end{array}$} & Pacifier & $\begin{array}{l}\text { "Remove their [clients'] pacifiers...information can pass through... } \\
\text { when clients are different...we remove them [pacifiers]...so we } \\
\text { can understand." (Ottawa participant) }\end{array}$ \\
\hline & $\begin{array}{l}\text { Bart Simpson's “No } \\
\text { Problem" lunchbox }\end{array}$ & $\begin{array}{l}\text { "Clients come with their 'no problemo' but are sick...all of their } \\
\text { baggage in the box... it'll fill itself as we help to explain what } \\
\text { the person has." (Toronto participant) }\end{array}$ \\
\hline \multirow[t]{2}{*}{$\begin{array}{l}\text { Changes in } \\
\text { professional } \\
\text { practice }\end{array}$} & Bonsai tree & $\begin{array}{l}\text { "We look for information....roots in the ground...try to make the } \\
\text { trunk...must reignite one's awareness constantly...make something } \\
\text { good...using the ancient with the new." (Sudbury participant) }\end{array}$ \\
\hline & Microphone & $\begin{array}{l}\text { "We're not listening enough to our clients...we talk too much... } \\
\text { we must learn their needs to have an impact...we must listen." } \\
\text { (Toronto participant) }\end{array}$ \\
\hline \multirow[t]{2}{*}{$\begin{array}{l}\text { Changes in } \\
\text { attitudes }\end{array}$} & Octopus & $\begin{array}{l}\text { "Multidimensional aspect...adapting oneself to all kinds of } \\
\text { people...more arms, more chances to reconnect one's } \\
\text { message." (Ottawa participant) }\end{array}$ \\
\hline & Pink princess shoe & $\begin{array}{l}\text { "Cultural aspect to health literacy...necessary to adapt one's } \\
\text { message to cultures." (Toronto participant) }\end{array}$ \\
\hline
\end{tabular}

Note: This table presents examples of thoughts from different participants' perspectives. The information in the table is not intended to indicate consensual meaning of the evocative objects. using medical jargon to disguise their lack of ability to decode English-language health information. Their ability to use medical jargon would protect them from professionals questioning their understanding of health information. Other participants reflected on the difficulties faced by francophone immigrants to Ontario who may not be able to read and write in French. They may also be unable to use the telephone system to seek urgent medical help or to access primary health care services. Being less familiar than nonimmigrants with the concept of preventing disease as it is applied in Canada, they may misunderstand disease-prevention initiatives. The participants suggested that the HL issues could be addressed by switching from disease-prevention health information that focuses on the probability of developing diseases to health-promotion information that focuses on ways to stay healthy.

\section{Organizational barriers to incorporating health literacy in practice}

During Exercise 2, the participants shared stories that revealed both the organizational barriers (e.g., necessarily fast pace of client consultations combined with professional usual use of medical jargon) and the ways they could apply HL in their practice. The participants agreed that professional language needs to be appropriate to the organizational setting and the literacy levels of clients and that communication styles need to be adapted to clients' cultures and literacy levels. The participants considered medical jargon in particular as a cause of inhibiting adherence, compliance and self-management as well as a barrier to clients using their own words to describe their symptoms. One participant remarked,

...because, if ever a doctor or any health professional, you try to explain to someone, as she said, the concept [it] took four hours [for us] to understand. And you try explaining it to [a client] in two minutes using very technical terms. [Sudbury participant]

The participants discussed the importance of talking to their clients in their first 
language. For example, some senior clients grew up speaking French at home and studying in both French and English and may prefer to speak French and read English. This discrepancy may be an issue in organizations that provide printed health information materials in only one language or that claim to provide bilingual services but verbally communicate only in English.

Better communication with clients was seen as a key strategy for improving the clinical and cultural appropriateness of professional efforts to enhance clients' HL. Some communication techniques (e.g. speaking slowly, repeating information and using simpler sentences) were defined as crucial to sustaining health knowledge among those clients who were unable to access services in French.

The participants also considered the organizational structure and culture within the health care system, particularly the lack of time and flexibility, as limiting the application of HL in professional practice. Specifically, there is not always enough time to explain concepts and address clients' nonverbal cues and complex social contexts. A Sudbury participant explained, "We find that it is very, very important to listen carefully to the language that people use-the verbal, the nonverbal-watch for little signs, how they speak. We should also find ways to increase our knowledge of our clientele." Another (Ottawa) participant suggested addressing time constraints by developing plans with clients and other professionals to change approaches to health information, care and service provision: "We need to anticipate and plan and take time with clients because we said that we are often limited. [For example,] if you go to your family doctor, you have eight minutes only."

Although the participants thought about ways to incorporate HL at individual and community-practice levels, they perceived fewer opportunities to do so at the organizational level, possibly because of budgetary constraints and decision makers' priorities. The feedback forms indicated a gain in 3 kinds of awareness about HL: as a concept, as a social determinant of health and as an individual, community and organizational support to improve health. Many participants wanted more workshops and opportunities to share knowledge with other professionals so as to expand their knowledge about and competencies in HL. Some requested in-service education on how to better reflect francophone cultural diversity in health and social services:

We need workshops that include cultural competencies. It is a big problem for those in our community, because the francophone community is very large. People come from all over, but they come with cultural differences. [Toronto participant]

\section{Analysis of evaluation study findings}

Freire's ${ }^{29}$ and Ekebergh's ${ }^{47}$ common ideas about learning about one's world and one's place in it through conscious selfreflection were the key inspirations for the analysis and interpretation of the workshop evaluation data. Both Freire and Ekebergh claim that distancing oneself from everyday experiences and critically reflecting on one's reality heightens critical consciousness. The workshop participants reflected on their experiential knowledge of francophone Canadians' struggles to access health information and services in French, and how HL influences both. The evocative objects that the facilitator gave to each participant and which prompted discussions about personal and professional experiences sparked these reflections. The participants discussed how delivery of health information affects clients' understanding and how clients apply health information to their self-care and self-management of their diseases. Our analysis of workshop evaluation data revealed three phenomena: (1) participants' broadened vision of HL, (2) changes in participants' attitudes to HL, and (3) pondering changes in professional practice.

\section{Participants' broadened vision of health literacy}

The workshop participants valued their experiential knowledge and new knowledge equally. They also shared an under- standing of power relations among professionals and between professionals and clients. The participants developed their vision of HL from its physical and mental dimensions to broader social and political dimensions. As they began to empathize with the experiences of low health literate clients, they acknowledged the stigma associated with poor comprehension of health information and the difficulty of making health decisions without understanding medical jargon or treatment options and consequences. In addition, clients can react emotionally and psychosocially when medical jargon is used to convey information to them, which can interfere with their understanding and ability to adhere to instructions and make decisions. ${ }^{48}$ Sharing ideas and experiences allowed the participants to become aware of how HL intersects with other social determinants of health and how these influence access to health and social services. ${ }^{48}$ This broadened vision of $\mathrm{HL}$, rooted in decoding the world and reflecting on it, may help to further promote it: ${ }^{49,50}$

This workshop has allowed me to understand the concept, the notion of health literacy, and has brought me to connect it to the other social aspects. [I understand that] literacy also embraces the cultural background and social constructions relating to disease and health care. [Ottawa participant]

\section{Changes in participants' attitudes to health literacy}

The group discussions revealed that the participants' attitudes to HL changed as a result of the workshop. Participants recognized that low HL among francophone clients was, in fact, a systemic problem that extended beyond the lack of availability of services in French and that important legal, ethical and administrative issues should be recognized and discussed in all social and health agencies that serve their clientele. The participants affirmed their intention to advocate for clients' rights to services and health information in French and to identify language-based service inequities. These intentions came from the better understanding of challenges that low health literate clients face 
with regard to all levels of care. In identifying barriers to client decisionmaking (e.g. lack of information, predictive skills, ability to understand risk), participants acknowledged their share of the responsibility to educate and support clients with respect to disease prevention and management while recognizing the influence of HL on clients' understanding:

I understand that the issue is larger than I thought, that it extends beyond reading and that it can be harmful to the health of individuals. [Toronto participant]

Self-reflection provoked more awareness (see Tables 3 and 4) of clients' right to services and health information in French within participants' own professional contexts and elsewhere. As difficult as they found it to recall professional knowledge prompted by the evocative objects, they realized the efficacy of these simple and playful objects in challenging their awareness. The objects evoked analogies and metaphors rich in meaning. As a result of this increased awareness about difficulties in communication, the participants identified time constraints, limited budgets, professional jargon, complex written materials and high service demands as ongoing challenges to client-centered care. Lack of time to fully explain concepts and treatment regimens was considered the main barrier to effective health communication. A greater awareness of the HL challenges faced by linguistic minorities motivated the participants to change their practice to incorporate plain language and allocate more time for listening to their clients.
Pondering changes in professional practice The workshop gave the participants opportunities to brainstorm about tools, competencies and strategies for promoting HL in their practice. Their disciplinary and cultural diversity may have enhanced the strength and validity of the strategies suggested as many were based on experience. Developing strategies and identifying tools demonstrated the participants' mastery of new resources for learning about and promoting HL. For example, community organizations are now using Twitter to promote HL and reinforce clients' understanding of basic health information. In addition, government agencies are giving more attention to cultural diversity in their Twitter-posted messages. ${ }^{51}$

The participants were able to call on their experiences as francophone professionals to critically evaluate research evidence related to HL and translate it in ways relevant to their practice. They even used their learning about HL to suggest new strategies that could improve services (see Table 5). Targeted scientific evidence should be considered when developing innovative interventions for low health literate people. ${ }^{52}$ Particular attention should be paid to clients' preferred means of communication (e.g. photo-novellas, videos). An approach that targeted clients' cultural preferences for health communication proved to be effective in reaching Canadian immigrants with asthma. ${ }^{53}$

The organizational environment that the participants described inadequately supports HL interventions; therefore, changes in professional practice require increased access to material and professional resources as organizational support, as recommended by DeWalt et al. ${ }^{54}$ Primary health care organizations should adopt quality improvement programs to implement HL interventions, “[...] promote services in French and promote health literacy, therefore develop this sensitivity and cultural competence, make it possible for staff to go on training, focus on the clients and find out what they need." [Ottawa participant]

Anticipated changes in practice were expressed in plans of action because the participants realized they possessed the experiential knowledge needed to promote and bring about such changes. By mastering the learning process they experienced, the participants may be able to replicate it with their clientele. Their own experience of decoding the potential meanings in each evocative object put them in a position similar to that of a client attempting to decode health information, thus raising their awareness of clients' struggles. This decoding, a primary aspect of HL, may influence how participants redesign their approach to educating clients in preventing and managing injuries and chronic diseases. The workshop awakened the participants' awareness of HL among linguistic-minority francophones and mobilized them to want to change their professional practice (see Table 5) as well as advocate for organizational change.

\section{Discussion}

Our literature review found no studies that reported on using evocative objects to have professionals reflect on learners' cultural worlds and lived experiences. ${ }^{31}$

\section{TABLE 4}

“Place Health Literacy at the Core of your Practice" workshop participants' thoughts on health literacy

\begin{tabular}{ll} 
Expanded knowledge about HL & \multicolumn{1}{c}{ Changed attitudes toward HL } \\
\hline $\begin{array}{l}\text { Interpreted blocks in clients' decision making } \\
\text { caused by lack of information, analytical } \\
\text { and predictive skills }\end{array}$ & $\begin{array}{l}\text { Acknowledging that communication with francophone } \\
\text { clients may require a more individual, slower pace } \\
\text { Understanding importance of using simple } \\
\text { language in communications with clients }\end{array}$ \\
$\begin{array}{l}\text { Acknowledging that a critical way of teaching is } \\
\text { necessary, one that respects clients' willingness } \\
\text { and ability to comprehend and safely apply } \\
\text { health information }\end{array}$ \\
$\begin{array}{l}\text { Intending to transmit health-related information in } \\
\text { ways that respect clients' cultural diversity }\end{array}$
\end{tabular}

Anticipated changes in professional practice to incorporate $\mathrm{HL}$

Mastering new resources for self-learning about $\mathrm{HL}$

Acquiring instrumental knowledge to change communication approaches

Envisioning new strategies to mobilize francophone communities and improve their $\mathrm{HL}$

Planning to enhance professional-client communication through two-way listening

Abbreviation: HL, health literacy. 
TABLE 5

Recommendations for incorporating health literacy into practice

\begin{tabular}{|c|c|}
\hline $\begin{array}{l}\text { Target } \\
\text { population }\end{array}$ & Workshop ${ }^{a}$ participants' and authors' recommendations \\
\hline \multirow[t]{3}{*}{ Professionals } & Make clientele aware of the concept of $\mathrm{HL}$ \\
\hline & Network to encourage dialogue among community practitioners about $\mathrm{HL}$ \\
\hline & $\begin{array}{l}\text { Share information to increase collective awareness of available } \mathrm{HL} \\
\text { resources and possible interventions }\end{array}$ \\
\hline \multirow[t]{2}{*}{ Managers } & $\begin{array}{l}\text { Foster organizational change to support professionals in adapting to their clients' } \\
\text { new social realities and in identifying HL needs at individual, community, } \\
\text { and organizational levels }\end{array}$ \\
\hline & Create organizational vision to address $\mathrm{HL}$ issues in linguistic minorities \\
\hline \multirow[t]{5}{*}{ Researchers } & $\begin{array}{l}\text { Design innovative methodologies to study emergent social issues interlinked with } \\
\text { HL, using expertise of professionals in direct contact with clientele }\end{array}$ \\
\hline & Identify organizational barriers to incorporating $\mathrm{HL}$ in professional practice \\
\hline & Explore opportunities to involve clients in decision-making and organizational change \\
\hline & $\begin{array}{l}\text { Design participatory action research that includes those who organize and deliver } \\
\text { health and social services, as well as clients, in francophone minority communities }\end{array}$ \\
\hline & Evaluate long-term impacts of similar workshops \\
\hline \multirow[t]{5}{*}{ Educators } & Strategize to demystify abstract, complex concepts for professionals \\
\hline & Create communication tools to link theory and practice \\
\hline & $\begin{array}{l}\text { Help professionals gain understanding, through participatory learning, } \\
\text { of theory underlying practice }\end{array}$ \\
\hline & $\begin{array}{l}\text { Promote activities to enhance knowledge about barriers to accessing information about } \\
\text { health and social services at client, professional, organizational, and system levels }\end{array}$ \\
\hline & $\begin{array}{l}\text { Offer similar workshops with francophone postsecondary students in health and social } \\
\text { sciences, giving them skills to advocate for better access to services for francophone } \\
\text { linguistic minority }\end{array}$ \\
\hline
\end{tabular}

Abbreviation: HL, health literacy.

a Placing Health Literacy at the Core of Your Practice.

Most studies of participatory-learning methods for training health care professionals do not provide details about the pedagogical theories and philosophies that underpin their methods. As a result, it is difficult to compare our findings with those of other studies. However, the literature does identify some learning strategies such as group discussion and interaction and role playing. ${ }^{55}$ Some studies also report on multidisciplinary community-services training that aims to integrate professional communication and collaboration among students in the health sciences and social services. ${ }^{56}$ Despite that the importance of language proficiency in clients' fully benefiting from health care and social services is recognized, this issue has been inadequately examined in the context of professional training. One example is a study by Sullivan et $\mathrm{al}^{30}$ of a series of 4 workshops to build professionals' capacity to communicate with a multilingual clientele where the main method used was group discussion. Another study applied Freire's educational principles through theatre, stories and pictures ${ }^{57}$ to educate community health workers about community organization and mobilization. ${ }^{58}$ Overall, the lack of information in several studies on workshop development does not allow further discussion of the appropriateness of other educational approaches to inservice education.

The findings of our evaluation study corroborate existing literature on systemic barriers faced by francophone professionals in responding to health and social conditions within francophone linguisticminority populations. ${ }^{59}$ In short, few organizations have mandates or formal mechanisms to directly address HL in their services. ${ }^{60}$ For most social service and health organizations, providing services (if any) for francophones remains the responsibility of anglophone stakeholders and decision makers. ${ }^{61}$ Health care professionals may assume that clients understand their advice because few clients request services in French. ${ }^{61}$ However, improving clients' HL education alone cannot eliminate communication barriers ${ }^{62}$ if professionals are not also educated ${ }^{63}$ in promoting the HL of linguistic minorities.

The workshop participants identified strategies to improve how they would disseminate health information. First, they suggested diversifying their pedagogy by using audio-visual materials, particularly for seniors. Second, they highlighted the importance of building stronger relationships with their clients and improving oral communication. Third, the participants considered HL to be a public health issue because it affects clients' ability to understand risks, manage their health conditions and engage in preventative and screening behaviours. This insight corroborates other research that argues that HL and general literacy, including the ability to understand risk and probability, are required to participate in public health initiatives. ${ }^{7}$ The participants emphasized the need for plain language communication, which is recommended best practice. $^{40,62,64}$ Although they acknowledged the need for improved communication and education materials, the majority of participants realized that collaborating with clients to develop solutions was unfeasible within the constraints of their work environment and the operations.

Fourth, the participants suggested in-service education to improve professionals' competency at addressing HL in their practices. As their competency improves, professionals may be more inclined to make sure that their clients understand health information and may be more likely to tailor education materials to lowliteracy clients. ${ }^{65}$

Finally, the participants learned that HL acts synergistically with language (including accents) and culture (including health beliefs, age, immigration status, social support, education and socioeconomic status). As a result, they identified a need for in-service education on cultural competencies and delivery of culturally relevant services that would promote professionals' involvement in developing, delivering and evaluating services. ${ }^{66}$ 
Equally necessary is cross-cultural healthcommunication education for health educators and consumers alike. ${ }^{67}$ However, confirming the findings of Herndon et al. ${ }^{24}$ participants disclosed that lack of time was a major organizational barrier to promoting HL.

Continuing to build awareness of HL matters if we are to increase professionals' ability to support their clients' HL. ${ }^{63}$ All health care professionals, including physicians and medical students, need more HL education. ${ }^{63}$ Nurses and nursing students, who typically teach clients but are less likely than physicians to assess clients' HL, ${ }^{68}$ need to be trained in simple ways to assess HL in primary health care. ${ }^{19,69}$ Since clients' HL can hardly be improved with continued use of printed health information in languages they have difficulty reading, non-print formats should be considered for low-literacy clients. $^{55,70}$

\section{Study limitations}

Our evaluation study has several limitations. First, organizational requirements to deliver bilingual services and the professional development goals set by the workshop participants themselves may have motivated them to attend the workshop. Second, we documented only the perspective of service providers, not of clients or directors of health and social services organizations. Third, impacts of the workshop were self-reported on feedback forms collected immediately after the workshop, a format vulnerable to enthusiastic reactions that may be subsequently tempered by reflection on the usefulness of the work.

There were also several potential biases in the study. First, the participants selfidentified as francophone professionals working with Franco-Ontarians, a situation that potentially sensitized them to the problems associated with HL. Second, the participants all worked in organizations mandated to serve francophones, which may have led to a sense of professional obligation to become aware of HL issues as lived by their francophone clients. Third, the researchers who worked with the verbatim transcripts were non-native
French speakers, which could have led to some misinterpretations of participants' accounts. To counteract this potential problem, native French speakers transcribed the audio-recordings and francophone researchers attended the workshop and participated in data analysis. A francophone cultural insider confirmed the final interpretation of findings.

\section{Conclusion}

Our workshop participants expressed their awakened awareness of HL as a collective accountability. By stating that they were all responsible for changing their work environments and their individual and collective practice, the participants affirmed the appropriateness of Freire's ${ }^{29}$ critical-pedagogy approach for the workshop. The collective accountability also corroborates our claim that critical pedagogy applied to in-service education effectively stimulates professionals' awareness of their potential to change their practice and work environments and to make social change. Professional development programs should support critical learning and offer meaningful tools for addressing the growing complexity of HL in multicultural and multilingual societies. These meaningful tools are ones that should make sense to professional learners. Freire ${ }^{71}$ advises that what we use to teach be meaningful for learners. Moreover, he describes an activity that is fundamentally formative for educators: critical reflection on their current practice and their visions for the future. ${ }^{71}$ This reflection should address educators' dreams, innovative ideas and objectives, all of which reveal the political roots of their educational undertaking. In the process of promoting HL, francophone professionals and their clients share the same social reality: living as a linguistic minority. Nevertheless, they may be unaware of the political import of this minority status for their own lives. Therefore, our use of Freire's critical-pedagogy approach was appropriate for promoting learners' autonomy in critiquing their social reality. It is their linguistic-minority status that guided our choice of philosophical approach, rather than empirical evidence from studies, which are often conducted with populations living in different cultural and linguistic settings.
Our findings may be transferable to other Canadian linguistic minorities and to organizations that provide them with health and social service policy development and to countries that lack second- or multiple-language policies.

Ontario health and social service professionals have developed expertise in working in multicultural contexts. As a result, our findings may be useful in similar practice contexts and in understanding how language, access to health and social services and other social determinants of health affect the health of linguistic minorities, including immigrants' health. ${ }^{72}$ The findings could inform health education initiatives for immigrant groups with low French or English proficiency. As well, evocative objects could be an appealing method for teaching other population groups such as those at risk of injury (for example, youth in seasonal sports) and for stimulating professionals to design appropriate ways to promote health in chronic disease populations.

\section{Acknowledgments}

We thank the health and social services professionals and students who participated in the workshop. We acknowledge the assistance of Dr. Manon Lemonde and Dr. Joëlle Fareau-Weyl in reviewing an early draft of the manuscript and Ms. Margaret Oldfield and Dr. Sylvia Novac for editing it.

There were no competing interests.

Financial support was provided by the Canadian Council on Learning, York Incentive Grant from York University, as well as Ryerson University's Undergraduate Research Opportunity fund and the Ryerson University Faculty of Community Services' Writing Week Initiative.

\section{References}

1. Barrett SE, Puryear JS. Health literacy: improving quality of care in primary care settings. J Health Care Poor Underserved. 2006;17(4):690-7. 
2. Gazmararian JA, Williams MV, Peel J, Baker DW. Health literacy and knowledge of chronic disease. Patient Educ Couns. 2003;51:267-75.

3. Cronin M, Connolly C. Exploring the use of experiential learning workshops and reflective practice within professional practice development for post-graduate health promotion students. Health Educ J. 2007;66(3): 286-303.

4. de Barros D, Barbieri AR, Ivo ML, et al. O contexto da formação dos agentes comunitários de saúde no Brasil. [The context of education of community health agents in Brazil]. Texto \& Contexto Enfermagem. 2010;19(1):78-84 (Portuguese).

5. Chávez V, Turalba RA, Malik S. Teaching public health through a pedagogy of collegiality. Am J Public Health. 2006;96(7): 1175-80.

6. Rootman I, Gordon-El-Bihbety D, Frankish $\mathrm{J}$, et al. National literacy and health research program: needs assessment and environmental scan. Ottawa (ON): Canadian Public Health Association; 2003.

7. Kaszap M, Zanchetta MS. La littératie en santé, vécue dans la simplicité mais comprise à travers la complexité : regard sur les communautés culturelles (francophones, minoritaires et multiethniques). In: Masny $\mathrm{D}$, ed. Les littératies multiples : lire au $21^{\mathrm{e}}$ siècle. Ottawa: Les Presses de l'Université d'Ottawa; 2009. pp. 287-325.

8. Forgues É, Landry R. Définitions de la francophonie en situation minoritaire : analyse de différentes définitions statistiques et de leurs conséquences. Ottawa (ON): Consortium National de Formation en Santé; 2006.

9. Bouchard L, Gaboury I, Chomienne M-H, Gilbert A, Dubois L. Health in language minority situation. Healthc Policy. 2009;4: 36-42.

10. Deveau K, Landry R, Allard R. Au-delà de l'autodéfinition. Composantes distinctes de l'identité ethnolinguistique. Francophonies d'Amérique. 2005;20:79-93.
11. Office of Francophone Affairs. Profile de la communauté francophone de l'Ontario 2009 [Internet]. Toronto (ON): Office of Francophone Affairs - The Ontario Trillium Foundation; 2009 [cited 2012 Mar 10]. Available at: http://docs.files.ontario.ca /documents/410/profil-des-francophones.pdf

12. Corbeil J, Lafrenière S. Portrait of officiallanguage minorities in Canada: Francophones in Ontario. Ottawa (ON): Statistics Canada; 2010 [Statistics Canada, Catalogue No.: 89642X].

13. Canadian Council on Learning. La littératie en santé au Canada: une question de bienêtre [Internet]. Ottawa (ON): Canadian Council on Learning; 2008 Feb 20 [cited 2009 Nov 29]. Available at: http://www .ccl-cca.ca/CCL/Reports/HealthLiteracy-2.html

14. Rootman I, El-Bihbety D. A vision for a health literate Canada: report of the expert panel on health literacy. Ottawa $(\mathrm{ON})$ : Canadian Public Health Association; 2008.

15. Papen U. Adult literacy as social practice: more than skills. New York (NY): Routledge; 2005.

16. Schonlau M, Martin L, Haas A, Derose KP, Rudd R. Patients' literacy skills: more than just reading ability. J Health Commun. 2011;16(10):1046-54.

17. St. Clair R. Why literacy matters - understanding the effects of literacy education for adults. Leicester (UK): National Institute of Adult Continuing Education; 2010.

18. Bouchard L, Desmeules M. Minorités de langue officielle du Canada. Québec: Presses de l’Université du Québec; 2011.

19. Berkman ND, Davis TC, McCormack L. Health literacy: what is it? J Health Commun. 2010;15(Suppl.2):9-19.

20. Howard DH, Sentell T, Gazmararian JA. Impact of health literacy on socioeconomic and racial differences in health in an elderly population. J Gen Intern Med. 2006;21(8): 857-61.

21. Zanchetta MS, Poureslami IM. Health literacy within the reality of immigrants' culture and language. Can J Public Health. 2006;97(Suppl.2):S26-30.
22. Canadian Council on Learning. State of learning in Canada: no time for complacency. Ottawa (ON): Canadian Council on Learning; 2007.

23. Baker DW. The meaning and the measure of health literacy. J Gen Intern Med. 2006;21(8):878-83.

24. Herndon JB, Chaney M, Carden D. Health literacy and emergency department outcomes: a systematic review. Ann Emerg Med. 2011;57(4):334-45.

25. Perlow E. Accessibility: global gateway to health literacy. Health Promot Pract. 2010;11(1):123-31.

26. Paasche-Orlow MK, Schillinger D, Greene SM, Wagner EH. How health care systems can begin to address the challenge of limited literacy. J Gen Intern Med. 2006;21(8):884-7.

27. Volandes AE, Paasche-Orlow MK. Health literacy, health inequality and a just healthcare system. Am J Bioeth. 2007;7 (11):5-10.

28. Rudd RE, Rosenfeld L, Simonds VW. Health literacy: a new area of research with links to communication. Atl J Commun. 2012;20(1): 16-30.

29. Freire P. Education for critical consciousness. New York (NY): Continuum; 1973.

30. Sullivan MF, Ferguson W, Haley HL, et al. Expert communication training for providers in community health centers. J Health Care Poor Underserved. 2011;22(4):135868.

31. Wallerstein N, Bernstein E. Empowerment education: Freire's ideas adapted to health education. Health Educ Q. 1988;5:379-94.

32. Wallerstein N. Powerlessness, empowerment, and health: implications for health promotion programs. Am J Health Promotion. 1992;6:197-205.

33. Freire P. Pedagogy of hope: reliving the pedagogy of the oppressed. New York (NY): Continuum; 2003.

34. Freire P. Educação como prática da liberdade [Education as practice of freedom]. $23^{\text {rd }}$ ed. Rio de Janeiro (BR): Paz e Terra; 1999 (Portuguese). 
35. Freire P. Educação e mudança [Education and change]. $23^{\text {rd }}$ ed. Rio de Janeiro: Paz e Terra; 1999 (Portuguese).

36. Freire P. Ação cultural para a liberdade e outros escritos [Cultural action for freedom and other writings]. $10^{\text {th }}$ ed. São Paulo: Paz e Terra; 2002 (Portuguese).

37. Racine L. Applying Antonio Gramsci's philosophy to postcolonial feminist social and political activism in nursing. Nurs Philos. 2009;10(3):180-90.

38. Schwandt TA. Constructivist, interpretivist approaches to human inquiry. In: Denzin NK, Lincoln YS, eds. Handbook of qualitative research. 1st ed. Thousand Oaks: Sage; 1994. pp. 118-37.

39. Tobin K, Tippins D. Constructivism as a referent for teaching and learning. In: Tobin $\mathrm{K}$, ed. The practice of constructivism in science education. Hillsdale: Lawrence Erlbaum; 1993. pp. 3-22.

40. Canadian Council on Learning. Health literacy in Canada: a healthy understanding. Ottawa (ON): Canadian Council on Learning; 2008.

41. Picard L, Allaire G. Deuxième rapport sur la santé des francophones de l'Ontario [Internet]. Sudbury (ON): Institute francoontarien, University Laurentienne; 2005 [cited 2008 Aug 10]. Available at: http:// www.sdhu.com/uploads/content/listings /rapport_sante_jan06.pdf

42. Freire P. Conscientização. Teoria e prática da libertação- Uma introdução ao pensamento de Paulo Freire [Conscientization: Theory and practice of liberation. An introduction to Paulo Freire's thoughts]. São Paulo: Centauro; 2001 (Portuguese).

43. Rossi PH, Lipsey MW, Freeman HE. Evaluation: a systematic approach. $7^{\text {th }}$ ed. Thousand Oaks: Sage; 2004.

44. Bardin L. L'analyse de contenu. $2^{\text {nd }}$ ed. Paris (FR): Quadrige/Presses Universitaires de France; 2007.

45. Sandelowski M. The call to experts in qualitative research. Res Nurs Health. 1998;21(5):467-71.
46. Canadian Council on Learning. Health literacy in Canada [interactive map of health literacy]. Ontario [Internet]. Ottawa (ON): Canadian Council on Learning; 2003 [cited 2008, Oct, 10]. Available at: http://www.ccl -cca.ca/cclflash/healthliteracy/map_canada_ e.html

47. Ekebergh M. Lifeworld-based reflection and learning: a contribution to the reflective practice in nursing and nursing education. Reflective Practice. 2007;8(3):331-43.

48. Roter DL. Oral literacy demand of health care communication: challenges and solutions. Nurs Outlook. 2011;59(2):79-84.

49. Zanchetta M, Kaszap M, Mohamed M, et al. Construction of Francophone families' health literacy in a linguistic-minority situation. Alterstice: Revue International de la Recherche Interculturelle. 2012;2 (2):47-62.

50. Wink J. Critical pedagogy: notes from the real world. $4^{\text {th }}$ ed. Saddle River; 2011.

51. Park H, Rodgers S, Stemmie J. Analyzing health organizations' use of Twitter for promoting health literacy. J Health Commun. 2013;18(4):410-25.

52. Sheridan SL, Halpern DJ, Viera AJ, Berkman ND, Donahue KE, Crotty K. Interventions for individuals with low health literacy: a systematic review. J Health Commun. 2011;16(Suppl.3):30-54.

53. Poureslami I, Rootman I, Doyle-Waters MM, Nimmon L, Fitzgerald JM. Health literacy, language, and ethnicity-related factors in newcomer asthma patients to Canada: a qualitative study. J Immigr Minor Health. 2011;13(2):315-22.

54. DeWalt DA, Broucksou KA, Hawk V, et al. Developing and testing the health literacy universal precautions toolkit. Nurs Outlook. 2011;59(2):85-94.

55. Hershberger PJ, Righter EL, Zryd TW, Little DR, Whitecar PS. Implementation of a process-oriented cultural proficiency curriculum. J Health Care Poor Underserved. 2008;19(2):478-83.

56. Nandiwada DR, Dang-Vu C. Transdisciplinary health care education: training team players. J Health Care Poor Underserved. 2010;21(1): 26-34.
57. Porr CJ, Mayan M, Graffigna G, Wall S, Vieira, ER. The evocative power of projective techniques for the elicitation of meaning. Int J Qual Meth. 2011;10(1):30-41.

58. Perez M, Findley SE, Mejia M, Martinez J. The impact of community health worker training and programs in NYC. J Health Care Poor Underserved. 2006;17 (1 Suppl):26-43.

59. Langille D, Rainham D, Kisely S. Is francophone language status associated with differences in the health services use of rural Nova Scotians? Can J Public Health. 2012;103(1):65-8.

60. Canadian Public Health Association. Perceptions of health literacy: results of a questionnaire for practitioners, policy-makers and researchers. Ottawa (ON): Canadian Public Health Association; 2007 Jan [cited 2010 May 7]. Available at: http://www .cpha.ca/uploads/portals/h-l/questionnaire e.pdf

61. Commissariat aux services en français de l'Ontario. Rapport annuel 2010-2011: un engagement partagé [Internet]. Toronto (ON): Commissariat aux services en français de l'Ontario; 2011 [cited 2012 Jun 5]. Available at: http://www.csf.gouv.on.ca/fr /rapport-annuel-2010-2011-un-engagement -partage

62. Sudore RL, Landefeld CS, Pérez-Stable EJ, Bibbins-Domingo K, Williams BA, Schillinger D. Unraveling the relationship between literacy, language proficiency, and patientphysician communication. Patient Educ Couns. 2009;75(3):398-402.

63. Coleman C. Teaching health care professionals about health literacy: a review of the literature. Nurs Outlook. 2011;59(2):70-8.

64. Herndon JB, Chaney M, Carden D. Health literacy and emergency department outcomes: a systematic review. Ann Emerg Med. 2011;57(4):334-45.

65. Schlichting JA, Quinn MT, Heuer LJ, Schaefer CT, Drum ML, Chin MH. Provider perceptions of limited health literacy in community health centers. Patient Educ Couns. 2007;69(1-3):114-20. 
66. Gillis D, Quigley A. Antigonish, N. S.: Taking off the blindfold: seeing how literacy affects health. Antigonish (NS): St. Frances Xavier University; 2004 Jun [cited 2008 Mar 10]. Available at: http://www .nald.ca/library/research/takngoff/takngoff .pdf

67. Kreps GL, Sparks L. Meeting the health literacy needs of immigrant populations. Patient Educ Couns. 2008;71(3):328-32.

68. Macabasco-O'Connell A, Fry-Bowers EK. Knowledge and perceptions of health literacy among nursing professionals. J Health Commun. 2011;16(Suppl.3):295-307.

69. Weiss BD, Mays MZ, Martz W, et al. Quick assessment of literacy in primary care: the newest vital sign. Ann Fam Med. 2005;3(6): 514-22.

70. Hasnain-Wynia R, Wolf MS. Promoting health care equity: is health literacy a missing link? Health Serv Res. 2010;45(4):897-903.

71. Freire P. Pedagogia da autonomia-Saberes necessários à prática educativa [Pedagogy of autonomy-Necessary knowledge for educational practice]. $43^{\text {rd }}$ ed. São Paulo (BR): Paz e Terra; 2011 (Portuguese).

72. De Maio FG. Understanding the health transitions of immigrants to Canada: research priorities. J Health Care Poor Underserved. 2012;23(3):958-62. 